\title{
Mathematical Modeling of High-risk Behaviors in Reformation and Social Assistance Centers
}

\author{
Nahid Khademi ${ }^{1}$, Malihe Khoramdad ${ }^{2}$, Ebrahim Shakiba ${ }^{3}$, Nasrin Barkhordar ${ }^{4}$, Hassan Rostamian ${ }^{5}$, Shahram \\ Saeidi $^{6}$, Alireza Zangeneh ${ }^{6}$ \\ ${ }^{1}$ CDC Department, Kermanshah Health Center, Kermanshah University of Medical Sciences, Kermanshah, Iran. \\ ${ }^{2} P h D$ students of epidemiology, Iran University of medical science, Tehran, Iran. \\ ${ }^{3} M D-P H D$, Faculty of Health, Kermanshah University of Medical Sciences, Kermanshah, Iran \\ Kermanshah, Iran. \\ ${ }^{4}$ MSc of general Psychology, Faculty of Health, Kermanshah University of Medical Sciences, \\ ${ }^{5}$ MSc of clinical Psychology, Faculty of Health, Kermanshah University of Medical Sciences, Kermanshah, Iran. \\ ${ }^{6}$ MSc of Geography and Urban Planning, Social Development and Health Promotion Research Center, Kermanshah University of Medi- \\ cal Sciences, Kermanshah, Iran. \\ *Corresponding author E-mail: eshakiba@kums.ac.ir
}

\begin{abstract}
There is an increasing rate of high-risk behaviors in women, particularly those in prisons and high-risk places. This study was aimed to determine the high-risk behaviors among women residing in reformation and social assistance centers of Kermanshah province, Iran. In this cross sectional study, 480 women living in reformation and social assistance centers, central prisons, social welfare centers, suburban areas, high-risk neighborhoods and hangouts; were randomly selected. The primary data were collected via demographic and highrisk behavior questionnaire. To detect HIV infection, a rapid test was used as well as ELISA test in suspected cases. Statistical analysis was performed using Chi Square and Pearson Correlation Coefficient tests. The most prevalent high-risk behaviors in the subjects were addictive drug abuse (73.5\%), arrest by judicial centers (59.2\%), illegitimate sexual contacts $(52.3 \%)$, and suicide (52.3\%), respectively. The rapid HIV test revealed a positive correlation co-efficiency between HIV-positive individuals with crystal meth abuse ( $\mathrm{r}=0.119$, $\mathrm{P}=0.035)$.Associations were also observed between smoking and narcotic drug abusing $(\mathrm{p}<0.001)$ and with drinking alcohol $(\mathrm{r}=0.265$, $\mathrm{p}<0.001$ ). A history of suicide with a history of imprisonment also showed a positive correlation. A high prevalence of drug abusing, illegitimate sexual contacts, as well as transmission of HIV infection due to high-risk sexual contacts and injection drug addiction among the women were among the most significant findings of the survey. These observations highlight the importance of the of authority's attention to design better policies and to implement them in order to reduce or prevent the resulting social harms.
\end{abstract}

Keywords: High-risk behaviors, Women, Iran, AIDS

\section{Introduction}

High-risk behaviors such as drug abuse, suicide, and unsafe sexual contacts are considered as one of the main complications of society. Emerging as serious concerns with an ascending trend in recent years, controlling these behaviors has remained the focus of social assistance authorities [1-3]. High-risk behaviors are potentially destructive behaviors which are autonomously conducted by individuals with or without awareness of their possible adverse consequences $[4,5]$. Intentional and unintentional injuries, smoking, alcoholism, high-risk sexual relationships, unhealthy nutritional behaviors, and insufficient physical activities; have been described as high-risk behaviors[6]. Women constitute a large part of global community, and this statistical fact has not been indeed practically generalized in all areas of human life. Of note, their contribution in social harms is completely reverse to their enjoyment of other human aspects. In other words, women are the first victims of many social deviations and injuries a part of which is the addiction[7]. Drug abuse, especially cigarette smoking is exceeding among women; which is a dangerous route to use other drugs and doing high-risk behaviors $[8,9]$. A previous study performed on
Iranian population with an average age of 17.41 years old reported that $12 \%$ and $3.5 \%$ of women had drug and alcohol abuse, respectively[10]. Another survey reported the drug abuse to be $15.6 \%$ in Iranian women[11].

AIDS is one of the most overwhelming diseases in the new era which has become a social and economic dilemma[2,3] in which the high-risk behaviors play a causative role[12]. Women with high-risk behavior are one of the most vulnerable groups to be infected with HIV $[2,3,13,14]$. According to the data reported by World Health Organization (WHO) the epidemic rate of HIV is alarmingly growing and it is estimated that this up-ward trend from 2002 to 2025 in countries like Iran can influence gross domestic product (GDP) to be decreased by 0.2 to $1.5 \%$ [15].

On the other hand, the studies have shown that Kermanshah has many health problems. Such as HIV/AIDS[2, 3, 13, 16], cancer[17], high fertility[18, 19], mortality[20, 21], low quality of life [22, 23] and lack of proper access to health centers[24-27]. As a result, it causes many health problems in the city. Also, elevated high-risk behaviors in the current community, underscores the significance of investigations in this regard. As women play central roles in families and participate in raising the children who control the future directions of societies, considering their 
behavioral health is of particular importance. Extensive studies have accomplished each of which have evaluated various aspects of high-risk behaviors; however, little has been focused on female population which requires further scrutiny for designing precise predictive policies in the community. Thus, our study was aimed to determine major high-risk behaviors in women living in reformation and social assistance centers of Kermanshah, a western province of Iran.

\section{Methods}

This cross sectional study was performed during 2016 on women residing in reformation and social assistance centers, suburban areas, high-risk neighborhoods, and hangouts of Kermanshah, Iran. Primarily, the high-risk places were identified which included central prison (Nesvan Prison Clause), shelters of female prostitutes, social assistance centers, social welfare affiliates, and suburban areas; in which a total of 480 women were randomly included in the study. The main criteria for including and excluding the subject in/from the study were the consent to participate, and failure to complete the major part of questionnaire, respectively. Following the complementary explanation of the projects, the subjects were given a written consent and anonymously asked to respond the closed-ended questions (mainly through a structured interview) asked by the trained experts of provincial healthcare center. The standard questionnaire included demographic information (age, marital status, education, place of living, and the caretaker job); and high-risk behaviors (smoking; alcohol drinking; drug abuse; the way of drug use; the type of addictive drug used; smoking, drinking, and drug abuse in one or more than one of the family members; suicide history; illegitimate or unsafe sexual contacts of subject or their husbands; history of temporal marriage, history of imprisonment). To detect HIV infection, a rapid test was used. An ELISA test was performed to confirm the primary results where necessary. In terms of addictive drugs, heroin, opium, hashish, amphetamines, and methadone etc. were included in questionnaire. The ways of drug administration classified as injection, oral, inhalation, and smoking. Even with one time injection trying, the subjects were categorized as injection drug abusers. For statistical analysis of the resulting data, the SPSS, Version 21, was applied using descriptive statistical methods (such as mean, standard deviation, frequency, and percentage), and analytical method including Chi Square, and Pearson Correlation Coefficient tests. A P-value of less than 0.05 was considered to be statistically significant.

\section{Results}

Our study included a total population of 480 women with an average age of $35.21 \pm 10.43$ years. The majority of the participants were 30-39 years old. In terms of marital status the women were $46.5 \%$ married and $18.4 \%$ of the participants were illiterate. The main cause for divorce was shown to be husband's addiction (Table1, 2).

Table 1: Demographic information of subjects

\begin{tabular}{|c|c|c|c|c|c|}
\hline variable & Age & Number $(\%)$ & variable & Education & Number $(\%)$ \\
\hline \multirow{6}{*}{ Age category } & $10 \_19$ years old & $24(5 \%)$ & \multirow{6}{*}{ Educational level } & illiterate & $88(18.4 \%)$ \\
\hline & 2029 years old & $124(26.1 \%)$ & & Elementary school & $142(29.6 \%)$ \\
\hline & $30 \_39$ years old & $174(36.6 \%)$ & & Intermediate school & $138(28.8 \%)$ \\
\hline & $40 \_49$ years old & $109(22.9 \%)$ & & High school & $89(18.6 \%)$ \\
\hline & 50 years old and more & $45(9.5 \%)$ & & College education & $22(4.6 \%)$ \\
\hline & All & $476(100 \%)$ & & All & $479(100 \%)$ \\
\hline \multirow{7}{*}{ Marital Status } & Single & $44(9.2 \%)$ & \multirow{7}{*}{ Divorce reason } & Husband's addiction & $76(42.2 \%)$ \\
\hline & Married & $223(46.5 \%)$ & & Husband's violence & $48(26.8 \%)$ \\
\hline & Divorced & $115(24 \%)$ & & Husband's poverty & $20(11.2 \%)$ \\
\hline & Widow & $66(13.8 \%)$ & & Involvement of Husband's parents & $10(5.6 \%)$ \\
\hline & Concubine & $32(6.7 \%)$ & & Woman's addiction & $12(6.7 \%)$ \\
\hline & \multirow{2}{*}{ All } & \multirow{2}{*}{$480(100 \%)$} & & Others & $14(7.8 \%)$ \\
\hline & & & & All & $180(100 \%)$ \\
\hline \multirow{4}{*}{ caretaker } & Husband & $46(9.6 \%)$ & \multirow{4}{*}{ Place of living } & City & $456(95.6 \%)$ \\
\hline & Father & $207(43.2 \%)$ & & \multirow{2}{*}{ Rural } & \multirow{2}{*}{$21(4.4 \%)$} \\
\hline & No caretaker & $192(40.1 \%)$ & & & \\
\hline & Others & $\begin{array}{c}34(7.1 \%) \\
79(100 \%)\end{array}$ & & All & $477(100 \%)$ \\
\hline
\end{tabular}

Noticeably, it was indicated that the time interval between marriage and divorce was less than one year in $2.7 \%, 1-2$ years in $5 \%$, $3-4$ years in $2.9 \%, 5$ years or more in $12.3 \%$ of divorced women.

Of all the participants, $47.5 \%$ were smokers, majority of whom $(44.2 \%)$ started the smoking during 16-20 years of life. diseases (mean age $47.1 \pm 10.2$ ) as controls.

Table 2: Frequency distribution of cigarette and water pipe smoking

\begin{tabular}{|c|c|c|c|c|c|}
\hline \multirow{2}{*}{\multicolumn{2}{|c|}{ variable }} & \multirow{3}{*}{ Number (\%) } & \multirow{2}{*}{\multicolumn{2}{|c|}{ variable }} & \multirow{3}{*}{$\begin{array}{l}\text { Number (\%) } \\
411(85.5 \%) \\
\end{array}$} \\
\hline & & & & & \\
\hline \multirow{3}{*}{ Smoking } & Yes & & \multirow{3}{*}{$\begin{array}{l}\text { History of smoking } \\
\text { in family }\end{array}$} & Yes & \\
\hline & No & $252(52.5 \%)$ & & No & $68(14.2 \%)$ \\
\hline & All & $480(100 \%)$ & & All & $479(100 \%)$ \\
\hline \multirow{6}{*}{$\begin{array}{l}\text { Starting age to } \\
\text { smoke }\end{array}$} & Bellow 10 years & $4(1.8 \%)$ & \multirow{3}{*}{ Water pipe smoking } & Yes & $222(46.4 \%)$ \\
\hline & $10-15$ years & $45(19.9 \%)$ & & No & $256(53.6 \%)$ \\
\hline & $16-20$ years & $100(44.2 \%)$ & & All & $478(100 \%)$ \\
\hline & $21-29$ years & $44(19.5 \%)$ & \multirow{7}{*}{$\begin{array}{l}\text { Starting age to use } \\
\text { water pipe }\end{array}$} & Bellow 10 years & $3(1.4 \%)$ \\
\hline & 30 years or more & $33(14.6 \%)$ & & $10-15$ years & $41(18.7 \%)$ \\
\hline & All & $226(100 \%)$ & & $16-20$ years & $97(44.3 \%)$ \\
\hline \multirow{4}{*}{$\begin{array}{l}\text { Daily number } \\
\text { of cigarettes }\end{array}$} & $1-10$ & $72(31.6 \%)$ & & 21-29 years & $39(17.8 \%)$ \\
\hline & $11-20$ & $90(39.4 \%)$ & & 30 years or more & $39(17.8 \%)$ \\
\hline & More than 20 & $66(28.9 \%)$ & & \multirow{2}{*}{ All } & \multirow{2}{*}{$219(100 \%)$} \\
\hline & All & $228(100 \%)$ & & & \\
\hline
\end{tabular}

Our findings showed that $35.4 \%$ of the subjects were alcoholics, $85.6 \%$ had smoker family members, and $39.8 \%$ had drug abuser parents. As the questionnaire showed, the types of drug in which the participants were addicted to were as follow: $27.2 \%$ opium, $15.9 \%$ heroin, $19.5 \%$ methamphetamine (crystal Meth), $25.5 \%$ methadone (with or without medical prescription), and $8.6 \%$ drugs. 
In this case, $3.3 \%$ of drug abusers selected "others" which include a range of other addictive or psychotropic drugs. Some others selected more than one drug in their questionnaire. The route of abusing drugs was stated to be smoking in $60.6 \%$, injection in $10.5 \%$, and in some cases more than a single route. It was deciphered that $59.2 \%$ of the participants had a history arrests in reformation centers, prisons or other judicial centers. Regarding the reason of the arrest, $12.8 \%$ declared it to be stealing, $3.7 \%$ for conflicts, $9.7 \%$ for illegitimate sexual contacts, $29.5 \%$ for beggary, $31.9 \%$ for drug dealing, $4.7 \%$ for murder, and $7.8 \%$ for other reasons.
It was shown that $6.9 \%$ of participants had their first sexual contact during $9-12$ years of age; $28.1 \%$ in $13-15$ years, $39.2 \%$ in 16 $19,18.3 \%$ in $20-25$ years, and $3.5 \%$ in more than 25 years. The average age range in which the women started: smoking, 21.16 \pm 7.95 ; alcohol: 20.86 \pm 5.86 ; sexual contact: 17.2 \pm 3.99 .

The most prevalent high-risk behaviors in women under study was indicated to be smoking, drug abuse, illegitimate sexual contact of women or their husband, alcohol abuse, history of temporary marriage, and abusing inject able drugs.

Furthermore, $15.2 \%$ of participants had one time suicide attempt; $19.3 \%$ had 2-10 times; and 2.7\% had more than 10 times attempts for suicide (Table 3 ).

Table 3: Frequency distribution of high-risk behaviors in the subjects

\begin{tabular}{|c|c|c|c|c|c|}
\hline \multicolumn{2}{|c|}{ variable } & Number (\%) & \multicolumn{2}{|l|}{ variable } & Number (\%) \\
\hline \multirow{3}{*}{ Drug abuse } & Yes & $353(73.5 \%)$ & \multirow{3}{*}{$\begin{array}{l}\text { History of arrest in reformation center, } \\
\text { prison or other judicial centers }\end{array}$} & Yes & $284(59.2 \%)$ \\
\hline & No & $127(26.5 \%)$ & & No & $169(40.8 \%)$ \\
\hline & All & $480(100 \%)$ & & All & $480(100 \%)$ \\
\hline \multirow{8}{*}{$\begin{array}{l}\text { Drug use meth- } \\
\text { od }\end{array}$} & Smoking & $312(60.6 \%)$ & \multirow{6}{*}{ Number of arrests } & Once & $124(44.5 \%)$ \\
\hline & Inhalation & $79(15.3 \%)$ & & Twice & $59(20.8 \%)$ \\
\hline & Oral & $70(13.6 \%)$ & & Tree times & $30(10.6 \%)$ \\
\hline & Injectable & $54(10.5 \%)$ & & Four times & $17(6 \%)$ \\
\hline & \multirow{4}{*}{ All } & \multirow{4}{*}{$515(100 \%)$} & & Five times or more & $51(18 \%)$ \\
\hline & & & & All & $283(100 \%)$ \\
\hline & & & \multirow{8}{*}{$\begin{array}{l}\text { The use of condoms in illegitimate sexual } \\
\text { contact }\end{array}$} & Always & $3(1.4 \%)$ \\
\hline & & & & Sometimes & $176(66.2 \%)$ \\
\hline \multirow{3}{*}{$\begin{array}{l}\text { Suicide attempt } \\
\text { history }\end{array}$} & Yes & $185(38.6 \%)$ & & Never & $51(19.2 \%)$ \\
\hline & No & $294(61.4 \%)$ & & \multirow{5}{*}{ All } & \multirow{5}{*}{$266(100 \%)$} \\
\hline & All & $479(100 \%)$ & & & \\
\hline \multirow{3}{*}{ Illegitimate sex } & Yes & $251(55.4 \%)$ & & & \\
\hline & No & $202(44.6 \%)$ & & & \\
\hline & All & 453(100\%) & & & \\
\hline
\end{tabular}

Regarding the reason for having illegitimate sexual contacts, $33.7 \%$ declared it to be for making money, $29 \%$ for providing addictive drugs, $15.9 \%$ to pay for accommodation, $6.3 \%$ were raped, and $15.1 \%$ for close relationship. The results of HIV rapid test in 5.3\% participant women was positive, while no syphilis positive sample was detected (Table 4).

Table 4: HIV and syphilis test results

\begin{tabular}{|c|c|c|c|c|c|}
\hline \multirow{4}{*}{ HIV } & Positive & $23(5.3 \%)$ & \multirow{4}{*}{ Syphilis } & Positive & - \\
\hline & Negative & $381(87.6 \%)$ & & Negative & $339(99.7 \%)$ \\
\hline & NA & $31(7.1 \%)$ & & NA & $1(0.3 \%)$ \\
\hline & All & $435(100 \%)$ & & All & $340(100 \%)$ \\
\hline
\end{tabular}

Of note, $95 \%$ of cigarette smokers had a simultaneous addiction to narcotic drugs. There was a significant correlation between cigarette and narcotic drug abusing $(\mathrm{p}<0.001)$, as the majority of drug abusers were smokers. Alcohol drink showed also a positive correlation with history imprisonment $(\mathrm{r}=0.311, \mathrm{p}<0.001)$. Moreover, the women with history of imprisonment were more likely to undergo suicide. Remarkably, $8.1 \%$ of those having unsafe sexual contact had a positive test result for HIV/AIDS; whereas no association between unsafe sexual behaviors and AIDS development was revealed $(\mathrm{P}=0.444)$. Drug abusage showed no statistical correlation with illegitimate sexual contact. Noticeably, $12.2 \%$ of crystal meth abusers had a rapid HIV test suggesting a significant positive correlation between theses parameters $(r=0.119, \mathrm{p}=0.035)$.

\section{Discussion}

In this study we have reported the high-risk behaviors in reformation and social assessment centers, suburban areas, high-risk neighborhoods, hangouts, central prison (Nesvan Prison Clause), places of beggar women, and social welfare affiliates. The most prevalent high-risk behaviors among the women under study were shown to be narcotic drug abusing, arrest by reformation or other judicial centers, illegitimate sexual contacts and suicide. Little is known about the addiction of women and the lack of sufficient knowledge is felt in this field. In this study, it was supported that opium is most likely narcotic drug to be used by the women. The most important reason to incline toward this was shown to be the close relationship with addicted family members, so that $42.5 \%$ of participants reported drug abusing with their husbands. Several

other previous reports have also confirmed that the addiction inside the family play essential role in women's addiction $[28,29]$. Inject able drug addiction was asserted to involve $10 \%$ of participants. This statistic was reported to be $9.8 \%$ for prisoner women of Birjand, Iran, and $3.1 \%$ for Isfahan women prisoners. Furthermore, a study made by McClelland et al. reported this in women of Chicago to be $18.8 \%[30,31]$. This variation can be as a result of different study population and sample volume. The HIV rapid test was positive in $5.3 \%$ of participants. Owing to the fact that inject able drug abusing has a significant causative effect on the spreading of viral diseases such as HIV and hepatitis; and that some reports verified that drug abuse in women especially injectable routs is most likely accompanied by escape from home, and prostitution (16); the fact that highlights the importance of attention to inject table addiction. Unsafe sexual contacts due to having the consequences such as pregnancy risk,spreading the infectious diseases, infection with HIV, and risk for developing cervix cancer; has been emphasized among high-risk behaviors[32]. Highrisk sexual behaviors impair mental health, emotional and behavioral balance. These behaviors include having multiple sex partners; and refuse of using options to prevent sexual transmitted disease. This risky behavior also brings some complications such as smoking, drug abusing, and alcohol drinking[33, 34]. More than $50 \%$ of women under study reported the illegitimate sexual behaviors, so that $35 \%$ of whom had 2-10 times of this behavior per month. Another study conducted in Isfahan, Iran which was exclusively performed on the women in prisons reported this highrisk behavior in $17 \%$ of participants[30]. This result variability may be due to the various sample size, the parameter which is large enough in our study in which we included women from sub- 
urban areas, hangouts, and reformation centers in addition to the prison. Having a high rate of HIV infections in the subjects with illegitimate and unsafe sexual contacts, paying attention to this issue is of a great importance; which requires fundamental preventive strategies. More than $30 \%$ of women in this study attributed their sexual contacts as an option for making money; thus promoting the welfare level in the society particularly in most vulnerable individuals can be considered as a method to reduce such these high-risk behaviors.

One of the findings of our survey was the high rate of suicide and the recurrent attempt to do so among the participants, which greatly differs from the prevalence reported by previous studies in Iran[35]. Nevertheless, the prevalence is remarkably high which necessitates further studies to control these abnormalities. The previous studies were mainly performed on imprisoned women which may not reflect a broad perspective of the prevalence of high-risk behaviors in whole society. We took benefit of a large sample size which included the women from different centers such as prison, reformation center, social welfare affiliates, and hangouts etc. difficulties to access to the study population and obtaining the Witten consent was among the study limitations. Unfortunately, rooting and deciphering the causative events of such high-risk behaviors were not possible in our survey, which need to be clarified in further assessments.

\section{Conclusion}

The high prevalence of illegitimate sexual contacts, addiction to narcotic drugs, as well as transmitting HIV infection due to unsafe sexual behaviors and injectable addiction are concerning issues which were observed in our study. Having a high prevalence among the women, these high-risk behaviors must be precisely taken into account by authorities and to be considered as their priorities. The accurate and persistent establishment of preventive strategies in prisons, reformation centers and among the women living in high -risk places need to be also ensured. The high prevalence of high-risk behaviors in the current society and its ascending trend in women highlight the importance of such studies to evaluate different aspects of these issues. Promising studies with minimum performance limitations are highly important to reduce the healthcare, social, and economic concerns in this context.

\section{Acknowledgment}

We kindly appreciate the research deputy of Kermanshah University of Medical Sciences for approving our research project and for their financial supports. We also thank to our colleagues in healthcare center of the province and to our participant for their patient responding to our questionnaire

\section{References}

[1] Slusky RI. Decreasing high-risk behavior in teens. A theater program empowers students to reach out to their peers. Healthcare executive. 2004;19(1):48-9.

[2] Khademi N, Reshadat S, Zangeneh A, Saeidi S, Ghasemi S, Rajabi-Gilan N, et al. A comparative study of the spatial distribution of HIV prevalence in the metropolis of Kermanshah, Iran, in 19962014 using geographical information systems. Hiv medicine. 2017;18(3):220-4

[3] Khademi N, Reshadat S, Zanganeh A, Saeidi S, Ghasemi S, Zakiei A. Identifying HIV distribution pattern based on clustering test using GIS software, Kermanshah, Iran. HIV \& AIDS Review. 2016;15(4):147-52.

[4] Corte CM, Sommers MS. Alcohol and risky behaviors. Annual review of nursing research. 2005;23:327.

[5] Abbasi P, Kianipour N ,Ziapour A. Correlation of the Components of Student's Lifestyles and their Health Promotion. Journal of Clinical and Diagnostic Research. 2018;12(6):LC01-LC4.
[6] DiClemente RJ, Salazar LF, Crosby RA. Health behavior theory for public health: Jones \& Bartlett Learning; 2018.

[7] Chesney-Lind M, Pasko L. The female offender: Girls, women, and crime: Sage; 2013.

[8] Dolatshahi B, Abasi I, Pahlavani H. Prevalence of high risk behaviors among women in Tehran. Practice in Clinical Psychology. 2016;4(2):105-12.

[9] Abbasi P, Kianipour N, Ziapour A. A Study of the Status of Students' Social Health at Kermanshah University of Medical Sciences and the Role of Demographic Variables. Journal of Clinical and Diagnostic Research. 2018;1(5):2VC10-VC4.

[10] Ahmadi J, Hasani M. Prevalence of substance use among Iranian high school students. Addictive behaviors. 2003;28(2):375-9.

[11] Najafi K, Zarrabi H, Shirazi M, Fekri F, Mohseni R. Prevalence of substance use among Iranian high school students in 2005-2006. Kuwait Med J. 2009;41(1):20-5.

[12] Tayeri K, KASAEIAN N, FADAEI NR, Ataei B. The prevalence of hepatitis $\mathrm{B}$, hepatitis $\mathrm{C}$ and associated risk factors in intravenous drug addicts (IVDA) with HIV in Isfahan.2008

[13] Reshadat S, Zangeneh A, Saeidi S, Khademi N, Izadi N, Ghasemi SR, et al. The Spatial Clustring Analysis of HIV and Poverty Through GIS in the Metropolis of Kermanshah, Western Iran. ACTA Medica Mediterranea. 2016;32:1995-9.

[14] Abbasi P, Timareh M, Ziapour A, Kianipour N. a study of the components of happiness and the role of demographic variables among the students at kermanshah university of medical sciences. Journal of Postgraduate Medical Institute. 2018;32(2):173-8.

[15] Nasirian M, Doroudi F, Gooya MM, Sedaghat A, Haghdoost AA. Modeling of human immunodeficiency virus modes of transmission in Iran. Journal of research in health sciences. 2012;12(2):81-7.

[16] Gooya MM, Soroush M, Khademi N, Mokhtari-Azad T, Janbakhsh A, Yeilaghi S, et al .An evaluation of the effects of influenza vaccination on HIV/AIDS-stricken patients in Kermanshah Province, Western Iran. Annals of Tropical Medicine and Public Health. 2017;10(3):628-32.

[17] Gazizov R., Nagovitsyna T. A., Political manipulation of The Media (on the example of mass media of the republic of Tatarstan, Astra Salvensis - review of history and culture, No. 10, 2017, p. 11-16.

[18] Reshadat S, Zangeneh A, Saeidi S, Ghasemi SR, Rajabi Gilan N, Abbasi S .Investigating the economic, social and cultural factors influencing total fertility rate in Kermanshah. Journal of Mazandaran University of Medical Sciences. 2015;25(127):108-12.

[19] Reshadat S, Zangeneh A, Saeidi S, Izadi N, Ghasemi SR, RajabiGilan N .A Feasibility Study of Implementing the Policies on Increasing Birth Rate with an Emphasis on Socio-economic Status: A Case Study of Kermanshah Metropolis, Western Iran. Social Indicators Research. 2018:1-18.

[20] Zangeneh A, Najafi F, Karimi S, Saeidi S ,Izadi N. Spatialtemporal cluster analysis of mortality from road traffic injuries using geographic information systems in West of Iran during 20092014. Journal of forensic and legal medicine. 2018;55:15-22.

[21] Nazari B, Bakhshi S, Kaboudi M, Dehghan F ,Ziapour A, Montazeri N. A Comparison of Quality of Life, Anxiety and Depression in Children with Cancer and Healthy Children, Kermanshah-Iran. International Journal of Pediatrics. 2017;5(7):5305-14.

[22] Ghasemi R, Rajabi-Gilan N, Reshadat S, Zakiei A, Zangeneh A, Saedi S. The relationship of social support and self-efficacy with mental health and life satisfaction. Journal of Mazandaran University of Medical Sciences. 2017;27(147):228-39.

[23] Kaboudi M, Kianipour N, Ziapour A, Dehghan F. A Study of Health Literacy Components and their Relationships with HealthPromoting Behaviors in Students at Kermanshah University of Medical Sciences. International Journal of Pediatrics. 2017;5(12):6721-29.

[24] Reshadat S, Saedi S, Zangeneh A, Ghasemi S, Gilan N, Karbasi A, et al. Spatial accessibility of the population to urban health centres in Kermanshah, Islamic Republic of Iran: a geographic information systems analysis. EMHJ-Eastern Mediterranean Health Journal. 2015;21(6):389-95

[25] Reshadat S, Saedi S, Zangeneh A, Amooie MR, Karbasi A. Equity in Access to Health Care Using Geographic Information System: a Kermanshah Case Study. Journal of Mazandaran University of Medical Sciences. 2014;24(115):134-40.

[26] Mohammadi E, Zaebi Y, Mousavi SH, Mahboubi M, Mohammadi M, Zangeneh A, et al. Emergency department performance evaluation indicators in pre and post-health care reform in kermanshah public hospitals. Research Journal of Medical Sciences. 2016;2(10): 54-9. 
[27] Kaboudi M, Dehghan F, Ziapour A. The effect of acceptance and commitment therapy on the mental health of women patients with type II diabetes. Annals of Tropical Medicine and Public Health 2017;10(6):1709-13

[28] Tuchman E. Women and addiction: the importance of gender issues in substance abuse research. Journal of addictive diseases. 2010;29(2):127-38.

[29] DiClemente CC. Addiction and change: How addictions develop and addicted people recover: Guilford Publications; 2018.

[30] Ataei B, Khorvash F, Azadeh S, Nokhodian Z, Kassaian N, Babak A. The Prevalence of High Risk Behaviors among Women Prisoners in Isfahan, Iran. Journal of Isfahan Medical School. 2011;29(150): 1-8

[31] Husnutdinov D. H., Aydarova S. H., Sagdieva R. K., Mirzagitov R. H., Tsaran A., Plotnikova H., Velikanova S. Information and Communication Tools for Tatar Language teaching, Astra Salvensis, Supplement No. 2, 2017, p. 15.

[32] Lam T, Stewart SM, Ho L. Prevalence and correlates of smoking and sexual activity among Hong Kong adolescents. Journal of Adolescent Health. 2001;29(5):352-8.

[33] 33Santelli J, Carter M, Orr M, Dittus P. Trends in sexual risk behaviors, by nonsexual risk behavior involvement, US high school students, 1991-2007. Journal of Adolescent Health. 2009;4.9-372:(4)4

[34] Bayrami M, Esmaili A. The comparison of factors and personality traits in sexually high risk and non high risk students. J Urmia Univ Med Sci. 2010;21(3):215-20.

[35] kikhavani S, Abdoli Y, MOHAMADZADAH J, Havasi M, Sharifi F, YEGANEH Z. Comparison of 91 Risk Factors for Suicide in Ilam Province in Comparison with the Trend in the Last 5 Years. 2015. 